\title{
Peningkatan Keterampilan Promosi Online Dodol Kelapa Sawit PKK Desa Alam Panjang
}

\author{
Desliana Dwita ${ }^{1 *}$, Wan Laura Hardilawati ${ }^{2}$, Novia Gesrian Tuti ${ }^{3}$ \\ ${ }^{1}$ Fakultas Ilmu Komunikasi, Universitas Muhammadiyah Riau \\ ${ }^{2}$ Fakultas Ekonomi dan Bisnis, Universitas Muhammadiyah Riau \\ ${ }^{3}$ Fakultas MIPA dan Kesehatan, Universitas Muhammadiyah Riau \\ email: deslianadwita@umri.ac.id
}

\begin{abstract}
Alam Panjang village is located in Rumbio Jaya District, Kampar Regency, Riau Province. One of the activities carried out by the PKK group in Desa Panjang Panjang is producing palm dodol. although it is quite popular, but not many people know it and it is only sold in the village of Alam Panjang and several neighboring villages. the proposer group tries to find a solution to the problem of unfamiliar oil palm dodol by providing training on promotional strategies through online media. The activity was carried out on September 10, 2019 at the Alam Panjang Village Office and was attended by 14 PKK members. methods carried out through approaches and training. The stages of the implementation of the activity starts from the preparation, implementation, monitoring and evaluation stages which focus on online promotion skills. in carrying out the activity, the proposing team is assisted by students consisting of students for documentation and preparation of activity equipment. For expertise, the proposing team consisted of three lecturers from different fields, Communication, Management and Biology. As a result of this activity participants gained knowledge and skills on how to promote through online media promotion. Although the participants were very enthusiastic, there was input from the participants that they wanted the training to be held again on the topic of how to make dodol more effectively. the partner group found it difficult to stir the dodol in the traditional way.
\end{abstract}

Kata Kunci: Alam Panjang Village, Palm Dodol, PKK Group, Online Media Promotion

\begin{abstract}
Abstrak
Desa Alam Panjang terletak di Kecamatan Rumbio Jaya, Kabupaten Kampar Provinsi Riau. Salah satu kegiatan yang dilakukan oleh kelompok PKK di Desa Alam Panjang adalah memproduksi dodol kelapa sawit. Meskipun cukup laku, namun dodol tersebut belum banyak yang mengenal dan hanya dijual di Desa Alam Panjang dan beberapa desa tetangga. Kelompok pengusul mencoba mencari solusi dari permasalahan kurang dikenalnya dodol kelapa sawit dengan memberikan pelatihan tentang strategi promosi melalui media online. Kegiatan dilakukan pada tanggal 10 September 2019 di Kantor Desa Alam Panjang dan diikuti oleh 14 orang anggota PKK. Metode yang dilakukan melalui pendekatan dan pelatihan. Tahapan pelaksanaan kegiatan dimulai dari tahap persiapan, pelaksanaan, monitoring dan evaluasi yang berfokus pada keterampilan promosi online. Dalam pelaksanaan kegiatan, tim pengusul dibantu oleh mahasiswa yang terdiri dari mahasiswa untuk dokumentasi dan penyiapan perlengkapan kegiatan. Untuk kepakaran, tim pengusul terdiri dari tiga orang dosen dari bidang ilmu yang berbeda yaitu Ilmu Komunikasi, Manajemen, dan Biologi. Hasil dari kegiatan ini peserta memperoleh pengetahuan dan keterampilan tentang cara promosi lewat media online. Meskipun peserta sangat antusias, namun terdapat masukan dari peserta yaitu mereka menginginkan diadakan kembali pelatihan dengan topik tentang cara membuat dodol yang lebih efektif. Kelompok mitra merasa kesulitan mengaduk dodol dengan cara tradisional.
\end{abstract}

Kata Kunci: Desa Alam Panjang, Dodol Kelapa Sawit, Kelompok PKK, Promosi Media Online 


\section{PENDAHULUAN}

Desa Alam Panjang terletak di Kecamatan Rumbio Jaya, Kabupaten Kampar Provinsi Riau. Luas wilayah Desa Alam Panjang adalah 3.600 Hektar. 70 persen wilayah Desa Alam Panjang merupakan daratan dengan topografi berbukit - bukit, sedangkan 30 persen lainnya merupakan daratan yang dimanfaatkan sebagai lahan pertanian yaitu untuk persawahan tadah hujan. Desa Alam Panjang beriklim tropis dengan dua musim yaitu musim kemarau dan musim hujan. Iklim ini berpengaruh langsung terhadap pola tananam pada lahan pertanian yang ada di Desa Alam Panjang Kecamatan Rumbio Jaya. [1]

Berdasarkan hasil sensus penduduk tahun 2015 yang diperoleh dari Buku Profil Desa Alam Panjang yang dimiliki Kantor Kepala Desa Alam Panjang, Desa Alam Panjang terdiri dari $822 \mathrm{KK}$, mempunyai jumlah penduduk 3.337 jiwa yang terdiri dari 1.734 jiwa laki-laki dan 1.643 jiwa perempuan. Desa Alam Panjang merupakan desa pertanian dengan perkebunan sawit dan karet sehingga sebagian besar penduduknya bermata pencarian sebagai petani.

Lahan pertanian dan perkebunan Desa Alam Panjang memiliki luas lebih kurang 983 Ha. Lahan tersebut ditanami dengan tanaman padi untuk pertanian dan kelapa sawit dan karet untuk perkebunan. Rinciannya adalah $100 \mathrm{Ha}$ untuk padi sawah, $5 \mathrm{Ha}$ untuk padi ladang, $130 \mathrm{Ha}$ untuk kelapa sawit, dan 748 Ha untuk karet. Hasil perkebunan kelapa sawit yang ada di Desa Alam Panjang pada umumnya dikirim ke pabrik untuk diolah menjadi minyak.

Disebabkan di desa ini terdapat banyak pohon kelapa sawit, maka kelompok PKK di Desa Alam Panjang mencoba kreativitas dengan membuat usaha bersama memproduksi dodol kelapa sawit. Penjualan dodol kelapa sawit yang diproduksi oleh anggota kelompok PKK Desa Alam Panjang hanya dilakukan ketika pameran. Setelah pameran berakhir, maka berakhir pula produksi dodol kelapa sawit tersebut. Menurut salah seorang anggota PKK yang ikut pameran, saat pameran berlangsung banyak konsumen dari Malaysia dan luar Provinsi Riau yang berminat dengan dodol tersebut. Namun, para konsumen tidak pernah memesan lagi karena komunikasi yang terputus. Promosi lewat media online yang kini banyak dilakukan untuk memperkenalkan dan menjual produk, belum dilakukan oleh anggota kelompok PKK. Padahal promosi sangat berguna untuk mengenalkan produk agar laku di pasaran.

Kegiatan promosi sebagai sarana komunikasi antara produsen dan konsumen untuk memperkenalkan produk, baik jenis, warna, bentuk dan harga, maupun kualitas produk yang ditawarkan atau yang dihasilkan perusahaan. [2]

Swastha (2002) dalam [2], promosi merupakan informasi kepada tindakan penukaran dan pembelian atau alat informasi satu arah bagi seseorang. Pada dasarnya promosi merupakan usaha dalam bidang informasi, menghimbau, membujuk dan komunikasi dan dapat dikatakan bahwa promosi merupakan pertukaran informasi dua arah antara pihak - pihak yang terlibat.

Setelah pameran selesai, penjualan dodol kelapa sawit oleh anggota PKK Desa Alam Panjang hanya dilakukan di Desa Alam Panjang dan beberapa desa tetangga. Produksi akhirnya menurun dan anggota kelompok menjadi tidak rutin membuat dodol.

Agar calon konsumen tertarik membeli dodol, kemasan juga harus dibuat menarik. Kemasan dodol kelapa sawit yang sangat biasa, hanya dengan bungkus plastik tanpa ciri khas tertentu, harus diperbaiki. Kemasan yang menarik juga menjadi hal penting ketika mempromosikan dodol lewat media online. [3]

Kemasan harus dapat menarik perhatian secara visual, emosional dan rasional. Sebuah desain kemasan yang bagus memberikan sebuah nilai tambah terhadap produk yang dikemasnya. Menurut penelitian, dari seluruh kegiatan penginderaan manusia, $80 \%$ adalah 
penginderaan melalui penglihatan atau kasatmata (visual). Karena itulah, unsurunsur grafis dari kemasan antara lain: warna, bentuk, merek, ilustrasi, huruf dan tata letak merupakan unsur visual yang mempunyai peran terbesar dalam proses penyampaian pesan secara kasatmata (visual communication).

Melalui Pengabdian Kemitraan Masyarakat Stimulus ini, pengusul bermaksud melakukan pendekatan dan memberikan pelatihan kepada anggota Kelompok PKK Desa Alam Panjang dalam mempromosikan dodol kelapa sawit agar usaha tersebut dikenal.

Prioritas kegiatan yang akan dilakukan pengusul adalah berfokus pada peningkatan pengetahuan dan keterampilan anggota PKK Desa Alam Panjang dalam mempromosikan dodol kelapa sawit. Disamping itu, agar dodol yang dipromosikan tersebut terlihat menarik, tim pelaksana juga memberikan pelatihan cara mengemas dodol kelapa sawit dengan kemasan yang lebih menarik. Mitra difokuskan pada kemampuan untuk melakukan promosi lewat media online dan mengemas dodol kelapa sawit dengan kemasan yang lebih menarik.

\section{METODE PENGABDIAN}

Dalam pelaksanaan Program Kemitraan Masyarakat Stimulus (PKMS) kepada kelompok mitra di Desa Alam Panjang, tim pelaksana melakukan beberapa metode dan strategi dalam rangka menyelesaikan permasalahan. adalah :

Beberapa metode yang dilakukan

1. Melakukan pendekatan yang bersifat himbauan tanpa unsur paksaan bagi anggota kelompok PKK agar ikut berperan aktif dalam pelaksanaan kegiatan pengabdian masyarakat ini. Tim pengusul berupaya agar anggota Kelompok PKK yang menjadi kelompok sasaran, termotivasi untuk mengikuti kegiatan yang dilakukan oleh tim pengusul.
2. Melibatkan masyarakat dalam keseluruhan kegiatan mulai dari perencanaan, pelaksanaan, monitoring dan evaluasi program kegiatan PKMS ini.

3. Melakukan pelatihan tentang promosi dodol kelapa sawit lewat media online.

4. Melakukan pelatihan tentang pengemasan produk dodol kelapa sawit yang menarik.

Tahapan pelaksanaan kegiatan dalam PKMS terdiri dari tahap persiapan dilakukan koordinasi dengan perangkat desa dan kelompok mitra sasaran guna pengumpulan data. Pada tahap ini juga dilakukan pendekatan pada masyarakat dan kelompok mitra agar ikut berpartisipasi dalam kegiatan yang akan dilaksanakan oleh tim pelaksana.

Tahap selanjutnya adalah pelatihan keterampilan mempromosikan dodol kelapa sawit lewat media online ditambah pelatihan keterampilan membuat kemasan dodol kelapa sawit menjadi unik dan menarik.

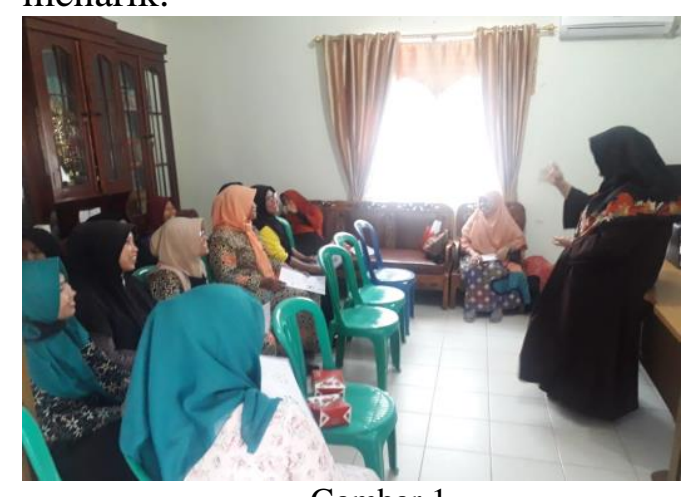

Penyampaian materi promosi dodol kelapa sawit lewat media online

Tahap selanjutnya yaitu monitoring dan evaluasi. Pada tahap ini dilakukan penyebaran angket kepada peserta untuk mengetahui tingkat keberhasilan kegiatan berdasarkan target yang telah ditetapkan. Selanjutnya dilakukan rapat oleh tim pelaksana untuk membahas hasil angket yang telah diperoleh dari isian peserta, serta membahas masukan dari peserta saat pelatihan berlangsung, untuk dijadikan bahan tema pengabdian selanjutnya. 
Tujuan evaluasi adalah untuk memperoleh informasi yang akurat dan objektif tentang suatu program. Informasi tersebut dapat berupa proses pelaksanaan program maupun hasil yang dicapai untuk mengambil keputusan apa yang harus diperbaiki untuk selanjutnya.[4]

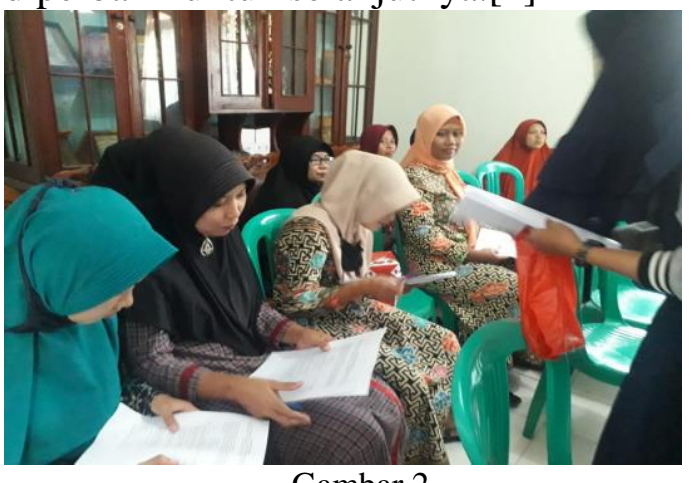

Gambar 2.

Pengisian angket oleh peserta pelatihan

Sumber daya manusia yang terlibat dalam kegiatan ini adalah dosen yang memiliki kepakaran untuk menyelesaikan persoalan kelompok mitra, serta mahasiswa yang membantu aspek teknis. Berikut disajikan dalam tabel :

Tabel 1. Kepakaran dan Tugas Tim Pelaksana PKMS

\begin{tabular}{|c|c|c|c|}
\hline Tim & Peran & $\begin{array}{c}\text { Kepakar } \\
\text { an }\end{array}$ & Deskripsi Tugas \\
\hline $\begin{array}{l}\text { Desliana } \\
\text { Dwita }\end{array}$ & Ketua & $\begin{array}{l}\text { 1. Komun } \\
\text { ikasi } \\
\text { 2. Kewira } \\
\text { usahaan }\end{array}$ & $\begin{array}{l}\text { 1.Mengorganisasikan } \\
\text { program } \\
\text { 2. Berkoordinasi } \\
\text { dengan mitra } \\
\text { 3. Perancangan } \\
\text { metode dan } \\
\text { pelaksanaan } \\
\text { 4. Perencanaan dan } \\
\text { pelaporan kegiatan } \\
\text { PKMS }\end{array}$ \\
\hline $\begin{array}{l}\text { Wan } \\
\text { Laura } \\
\text { Hardila } \\
\text { wati }\end{array}$ & $\begin{array}{l}\text { Anggo } \\
\mathrm{Ta}\end{array}$ & $\begin{array}{l}\text { 1.Pemasar } \\
\text { an } \\
\text { 2.Kewirau } \\
\text { sahaan }\end{array}$ & $\begin{array}{l}\text { 1. Merancang strategi, } \\
\text { metode pelatihan dan } \\
\text { narasumber strategi } \\
\text { promosi lewat media } \\
\text { online } 2 \text {. Membantu } \\
\text { berkoordinasi dengan } \\
\text { pihak-pihak terkait }\end{array}$ \\
\hline $\begin{array}{l}\text { Novia } \\
\text { Gesrian } \\
\text { Tuti }\end{array}$ & $\begin{array}{l}\text { Anggo } \\
\mathrm{Ta}\end{array}$ & $\begin{array}{l}\text { 1.Biologi } \\
\text { 2.Penge } \\
\text { masan } \\
\text { produk }\end{array}$ & $\begin{array}{l}\text { 1. Pelaksana pelatihan } \\
\text { pengemasan produk } \\
\text { 2. Menyusun } \\
\text { perencanaan dan } \\
\text { laporan hasil evaluasi } \\
\text { program PKMS. }\end{array}$ \\
\hline
\end{tabular}

\section{HASIL DAN PEMBAHASAN}

Program Pengabdian Kemitraan Masyarakat Stimulus (PKMS) telah dilaksanakan pada hari Selasa tanggal 10 September 2019 pukul 15.00 - 17.00 WIB. Sebanyak 14 orang anggota PKK Desa Alam Panjang mengikuti pelatihan tentang promosi dodol kelapa sawit melalui media online dan cara pembuatan kemasan dodol yang menarik. Acara dilaksanakan di Kantor Desa Alam Panjang.

Dalam kegiatan tersebut, kelompok mitra mengikuti dengan semangat dan antusias. Beberapa masukan dari peserta diantaranya menginginkan diadakan kembali pelatihan dengan topik cara membuat dodol yang lebih efektif. Hal ini karena kelompok mitra masih kesulitan mengaduk dodol dengan cara tradisional.

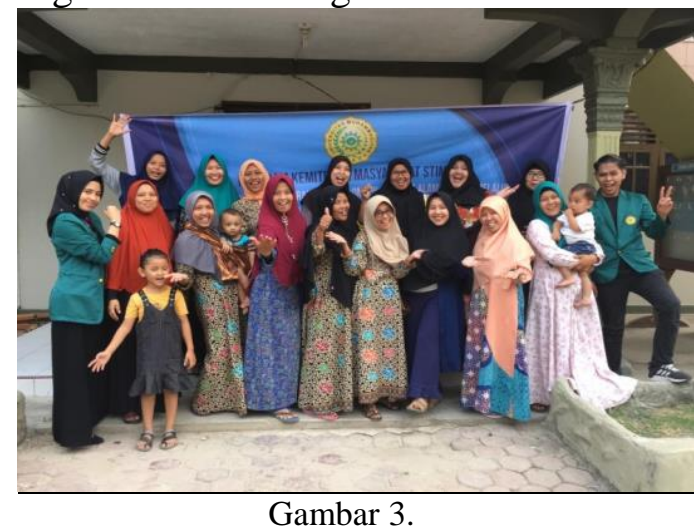

Foto Bersama Anggota PKK Desa Alam Panjang

Pada akhir acara, tim pelaksana memberikan kenang-kenangan kepada peserta karena telah mengikuti pelatihan dengan antusias. Untuk mengetahui tingkat penambahan pengetahuan dan keterampilan peserta, tim pelaksana membagikan angket tentang hasil yang mereka dapatkan dari mengikuti pelatihan. Dari hasil angket didapatkan bahwa peserta menyatakan memperoleh pengetahuan dan keterampilan tentang cara promosi melalui media online serta mengemas produk yang menarik.

\section{SIMPULAN}

Pelaksanaan kegiatan pelatihan tentang strategi promosi dodol kelapa sawit di media online dan cara membuat kemasan dodol yang menarik oleh tim pelaksana PKMS UMRI telah menghasilkan peningkatan pengetahuan dan keterampilan 
anggota kelompok PKK Desa Alam Panjang.

Untuk kegiatan pengabdian selanjutnya diupayakan pelaksanaan kegiatan bagi anggota PKK Desa Alam Panjang berupa pelatihan tentang cara membuat dodol kelapa sawit yang lebih efektif dengan peralatan yang lebih praktis.

\section{UCAPAN TERIMA KASIH}

Tim Pelaksana Mengucapkan Terima Kasih Kepada Universitas Muhammadiyah Riau Melalui Lembaga Penelitian Dan Pengabdian Masyarakat (LPPM) Yang Telah Memberikan Dana Hibah Sehingga Kegiatan PKMS Ini Dapat Terlaksana.

Tim Pelaksana Juga Mengucapkan Terima Kasih Kepada Dekan Fakultas Ilmu Komunikasi, Dekan Fakultas Ekonomi Dan Bisnis, Serta Dekan Fakultas MIPA Dan Kesehatan Universitas Muhammadiyah Riau Yang Telah Memberikan Kesempatan Untuk Tim Pelaksana Mengadakan Kegiatan PKMS.

Tim Pelaksana Juga Mengucapkan Terima Kasih Kepada Kepala Desa Alam Panjang Serta Ketua Dan Anggota PKK Desa Alam Panjang, Kecamatan Rumbio Jaya Kabupatan Kampar Atas Kerja Sama Yang Terjalin Dengan Baik Hingga Kegiatan PKMS Dapat Terlaksana.

\section{DAFTAR PUSTAKA}

[1] R. Febronika, A. Rifai, And J. Yusri, "Analisis Produktivitas, Pendapatan Dan Kesejahteraan Petani Karet Eks Upp Tcsdp Kualu Di Desa Alam Panjang Kecamatan Rumbio Jaya Kabupaten Kampar," Jom Faperta, Vol. 2, No. 1, Pp. 1-14, 2015.

[2] A. Jamaludin, Z. Arifin, And K. Hidayat, "Pengaruh Promosi Online Dan Persepsi Harga Terhadap Keputusan Pembelian (Survei Pada Pelanggan Aryka Shop Di Kota Malang)," J. Adm. Bisnis, Vol. 21, No. 1, Pp. 1-8, 2015.

[3] C. S. Cenadi, "Peranan Desain Kemasan Dalam Dunia Pemasaran,"
Nirmana, Vol. 2, No. 1, Pp. 92-103, 2000.

[4] S. E. P. Widoyoko, "Evaluasi Program Pembelajaran (Instructional Program Evaluation)," Umpwr.Ac.Id, 2009. 